\title{
dc magnetometry of niobium thin film superconductors deposited using high power impulse magnetron sputtering
}

\author{
S. Wilde, ${ }^{1,3}$ R. Valizadeh, ${ }^{1}$ O. B. Malyshev, ${ }^{1}$ G. B. G. Stenning, ${ }^{2}$ T. Sian, ${ }^{1,4}$ and B. Chesca ${ }^{3}$ \\ ${ }^{1}$ ASTeC, STFC Daresbury Laboratory, Warrington, WA4 4AD Cheshire, United Kingdom \\ ${ }^{2}$ ISIS, STFC Rutherford Appleton Laboratory, Didcot OX11 OQX, United Kingdom \\ ${ }^{3}$ Department of Physics, Loughborough University, Loughborough LE11 3UE, United Kingdom \\ ${ }^{4}$ The University of Manchester, Manchester M13 9PL, United Kingdom
}

(Received 16 April 2018; published 20 July 2018)

\begin{abstract}
We performed a systematic investigation of the dc magnetic properties of superconducting niobium thin films deposited by high power impulse magnetron sputtering (HiPIMS) as a function of the main deposition parameters: the temperature, $\mathrm{T}$, of the heated substrate and the applied dc bias voltage, $\mathrm{V}$, during the sputtering process. The measured dc magnetization curves between 0 and $1000 \mathrm{mT}$ were used to calculate the relative volume of each sample into which the applied magnetic field had penetrated, $(\Delta \mathrm{V} / \mathrm{V})_{M}$. The sample deposited at $700^{\circ} \mathrm{C}$ with $-80 \mathrm{~V}$ biased substrate exhibited the least penetration by the magnetic field. $(\Delta \mathrm{V} / \mathrm{V})_{M}$ appeared to be highly dependent on the bias voltage at both room temperature and $500^{\circ} \mathrm{C}$; however, a broad range of bias voltages showed comparatively similar results at increased temperatures of $700^{\circ} \mathrm{C}$. Samples deposited at $700^{\circ} \mathrm{C}$ exhibit smaller upper critical fields, $\mathrm{H}_{C 2}$, than samples deposited at room temperature and $500^{\circ} \mathrm{C}$, with the lower temperatures exhibiting a greater dependency on the applied bias. The films deposited at $700^{\circ} \mathrm{C}$ also display a more stable magnetization curve suggesting that an enhanced flux pinning was achieved when compared to lower temperatures. Consequently, films with stable pinning were found to have the most repeatable dc magnetic behavior. Our results are particularly relevant to the superconducting radio-frequency accelerator scientific community where thin films have been suggested as a technology which may ultimately surpass the performance of bulk niobium. They are also relevant to the fundamental area of superconducting thin films and any applied area where thin films produced by HiPIMS are used, such as superconducting electronics.
\end{abstract}

DOI: 10.1103/PhysRevAccelBeams.21.073101

\section{INTRODUCTION}

There are three parameters which can be used to rate superconducting radio-frequency (SRF) cavity performance, the maximum attainable acceleration gradient, E, above which the cavity will quench, the attainable quality factor, Q, as a function of the accelerating field and its maximum $\mathrm{Q}_{0}$.

The theoretical limit of acceleration gradient is capped at the superheating field $\left(\mathrm{H}_{\mathrm{SH}}\right)$ as it is the upper limit to which a superconductor can remain in the Meissner state. Current technology already allows bulk niobium test cavities to reach accelerating fields which are close to the $\mathrm{H}_{\mathrm{SH}}$ of niobium with a corresponding magnetic field strength, $\mathrm{H}$, of $220 \mathrm{mT}$ [1]. New surface treatments such as nitrogen doping have improved the quality factor of bulk niobium cavities however

Published by the American Physical Society under the terms of the Creative Commons Attribution 4.0 International license. Further distribution of this work must maintain attribution to the author(s) and the published article's title, journal citation, and DOI. at the expense of a reduction in the maximum acceleration gradient [2]. High field nonlinear dissipation could explain the monopoly of bulk niobium in SRF applications since niobium has the highest value of the first critical field, $\mathrm{H}_{C 1}$ (around $175 \mathrm{mT}$ at a temperature of $2 \mathrm{~K}$ ) among all superconductors: high $\mathrm{H}_{C 1}$ material is mandatory to prevent early vortex penetration on surface defects. Attempts to use superconductors with higher critical temperature, $\mathrm{T}_{C}$, or upper critical field, $\mathrm{H}_{C 2}$, have failed so far, due to their low values of $\mathrm{H}_{C 1}$, which allows early penetration of magnetic vortices resulting in high surface dissipation.

Superconducting thin films have been suggested as a technology which may ultimately surpass the performance of bulk niobium. The best niobium thin film cavities have already achieved higher $\mathrm{Q}$ at low fields than that of bulk niobium [3]. Thin film cavities have also been shown to be less sensitive to trapped flux when compared to bulk niobium [4]. "Dirty" niobium thin films with large Ginzburg-Landau parameters can be integrated into multilayer superconductor-insulator-superconductor films which have been proposed as a way to use magnetic shielding layers to increase both acceleration gradient and Q factor [5]. Other benefits of superconducting thin films are the 
possibility of substrates such as oxygen-free copper to dissipate heat more efficiently than bulk niobium and which are less expensive than bulk niobium therefore reducing material costs [6].

The current capabilities of thin film niobium only allow its use for low field application. Q factors become unacceptably small above $17 \mathrm{MV} \mathrm{m}^{-1}$. There are theories regarding the mechanisms which explain the sharp Q(E) slope; however, none are widely accepted as unequivocally proven $[4,7-10]$. It is therefore imperative that thin film niobium is fully characterized using a wide range of analytical techniques to fill in the gaps in our scientific understanding towards the goal of erasing the Q slope.

The objective of this study was to systematically analyze the dc magnetic properties of niobium thin films deposited by HiPIMS as a function of the deposition parameters. Some preliminary results have been reported by us previously [11-13]. HiPIMS is a variant of the commonly used pulsed dc sputtering. However HiPIMS achieves much higher target currents by using short pulses and comparatively long off times. The resulting HiPIMS plasma can have peak currents which are up to 2 orders of magnitude larger than dc. The enhanced plasma current at the target surface allows for a high ion to neutral ratio of the target material and synthesizes comparable films to ion assisted deposition [14]. The effect of changing both the substrate temperature and bias voltage will have been to change the surface mobility of sputtered material arriving at the substrate [15], allowing us to study the influence of temperature and ion bombardment on the rates of production and annihilation of defects.

\section{EXPERIMENTAL}

\section{A. Sample preparation and deposition}

The niobium thin films were each deposited onto asreceived polycrystalline oxygen-free copper substrates. Each substrate disk was $2 \mathrm{~mm}$ thick with a diameter of $52 \mathrm{~mm}$. The substrates were first cleaned in ultrasonic baths of acetone, then isopropanol, then methanol and finally rinsed with deionized water.

The HiPIMS deposition facility consists of two chambers: deposition and loadlock chambers. Up to seven samples can be inserted into the cartridge inside the loadlock vacuum chamber. Prior to deposition, the entire deposition facility was baked to $150^{\circ} \mathrm{C}$ for four days; the base pressure of $5 \times 10^{-10}$ mbar was reached after cooling to room temperature. Inserting multiple sample substrates into the loadlock vacuum chamber allows one baking of all samples without the need to vent and bake the system between depositions. After all samples are deposited then new substrates are inserted and only the loadlock vacuum chamber was baked again.

Films were deposited by HiPIMS using a water cooled three-inch planar magnetron which was oriented at $45^{\circ}$ from the substrate plane. The target material was $99.95 \%$ purity niobium. The distance between the substrate and target was $150 \mathrm{~mm}$. Krypton sputter gas was used at a pressure of $7 \times 10^{-3}$ mbar. Krypton was chosen because it is purer than commercially available argon whilst is less costly than xenon. Krypton has been shown to produce sputtered niobium films which contain lower volumes of implanted sputter gas atoms when compared to the other noble gases [4]. The sample substrate was set to continuously rotate at $4 \mathrm{rpm}$.

The HiPIMS power supply was set to pulse with constant settings for every deposited film. The voltage was set to pulse at $200 \mathrm{~Hz}$ with a pulse length of $100 \mu \mathrm{s}$. The average current was maintained at $600 \mathrm{~mA}$ which resulted in peak currents for each pulse of approximately 40 A. Each deposition was performed for $4 \mathrm{~h}$ resulting in the film thickness of approximately $1.4 \mu \mathrm{m}$.

The variable parameters of the experiment were the substrate temperature and a dc substrate bias voltage. Eighteen samples were deposited in total. Two main deposition parameters were varied, sample temperature and the bias applied to the sample substrate. Samples were deposited at room temperature, $500^{\circ} \mathrm{C}$ or $700^{\circ} \mathrm{C}$ with either a grounded substrate, or with an applied dc bias of -20 , $-50,-80,-100$ or $-120 \mathrm{~V}$. The desired substrate temperature was reached $30 \mathrm{~min}$ prior to the start of film deposition so that the substrate temperature was homogeneous once the film began to grow.

\section{B. dc magnetic hysteresis measurements}

All deposited niobium films were analyzed using a quantum design MPMS XL-7 to measure magnetic hysteresis loops in a dc magnetic field at $4.2 \mathrm{~K}$. In application to SRF cavities, the magnetic field should be parallel to the surface. All samples were oriented as close to parallel to the plane of the magnetic field as was possible to achieve. The error in the sample alignment with the magnetic field was $\pm 1^{\circ}$ ( $\left.\pm 17 \mathrm{mrad}\right)$.

The sensitivity of the Magnetic property measurement system (MPMS) system is $10^{-7} \mathrm{emu}$; however, in the reported experiment the noise level of the magnetic moment measurements was observed to be $10^{-4} \mathrm{emu}$ at zero field.

Signal to noise ratio can be increased by increasing the sample volume. Since the volume of deposited thin films is very small then copper substrates were first etched from the films using nitric acid so that the sample thickness could be reduced, allowing three $5 \pm 1 \mathrm{~mm} \times 5 \pm 1 \mathrm{~mm}$ pieces of the same film to be placed one on top of another inside the MPMS measurement space and then enhance the signal. The nitric acid was of $>99.99 \%$ purity with a concentration of $70 \%$ and was mixed in a ratio of $1: 1$ with deionized water.

\section{Residual resistivity ratio}

The residual resistivity ratio (RRR) was measured for each deposited film. RRR is the ratio of the resistance of the 
sample at 300 and $10 \mathrm{~K}$. Samples with the largest RRR have the fewest defect or impurity densities.

Each sample was measured using a purpose built fourpoint probe by passing $10 \mathrm{~mA}$ through the outer current probes and measuring the voltage drop across the inner probes, allowing the resistance to be calculated. The substrate was first etched from each sample using the same process as for the dc magnetic measurements to ensure the resistance of the copper was not measured. The resistance was measured every $5 \mathrm{~s}$ as each sample was cooled from room temperature down to below its superconducting transition temperature $\left(\mathrm{T}_{C}\right)$.

\section{Morphological characterization}

Each deposited film was analyzed by grazing incidence $\mathrm{x}$-ray diffraction (GI-XRD) at an angle of $2^{\circ}$. Samples were measured with a Bruker D8 Discover system using a cobalt $\mathrm{x}$-ray source to produce radiation with a wavelength of $1.78901 \AA$. Niobium thin film samples were measured both still attached to the copper substrate and after the copper substrate had been etched away.

The angle of the largest diffraction peak (preferred growth orientation), $\theta$, from each measurement was used to calculate the lattice parameter, $a_{0}$, of each film by first using Eq. (1) to calculate the lattice spacing, $d$, and then Eq. (2) to calculate $a_{0}$. A relative difference in the length of the lattice parameter from one film to another suggests disparity in the inherent film stresses, where the stress is attributed to the distribution of defects as the film grows:

$$
\begin{gathered}
n \lambda=2 d \sin \theta \\
a_{0}=\frac{d_{h k l}}{\left(h^{2}+k^{2}+l^{2}\right)} .
\end{gathered}
$$

A selection of films were also imaged by scanning electron microscope (SEM). Images were taken of the film surface using a backscatter detector to give a better understanding of the film microstructure.

\section{RESULTS}

\section{A. First quadrant hysteresis}

The results of magnetization measurements are shown in Figs. 1(a), 1(b) and 1(c) for the samples deposited at room temperature, $500{ }^{\circ} \mathrm{C}$ and $700^{\circ} \mathrm{C}$, respectively. Each figure displays results for bias voltages of $0,-20,-50,-80$, -100 and $-120 \mathrm{~V}$. Measurements start at $0 \mathrm{mT}$ and stop at fields above $\mathrm{H}_{C 2}$. The measured magnetic moment, $\mathrm{M}$, displays an initial linearity as a function of applied field, $\mathrm{H}$, followed by a varying rate of change in the measured moment before reaching its maximum value and finally falling back to zero. Only a selection of samples exhibit smooth curves, deposited at $700^{\circ} \mathrm{C}$ with bias voltages of $-80,-100$ and $-120 \mathrm{~V}$. Multiple small value magnetic flux jumps can be observed in all other samples. Such flux jumps represent unstable flux pinning and rapid reorientation of vortices into more energetically stable pinning locations as the magnetic field strength changes as discussed later in Sec. IV.
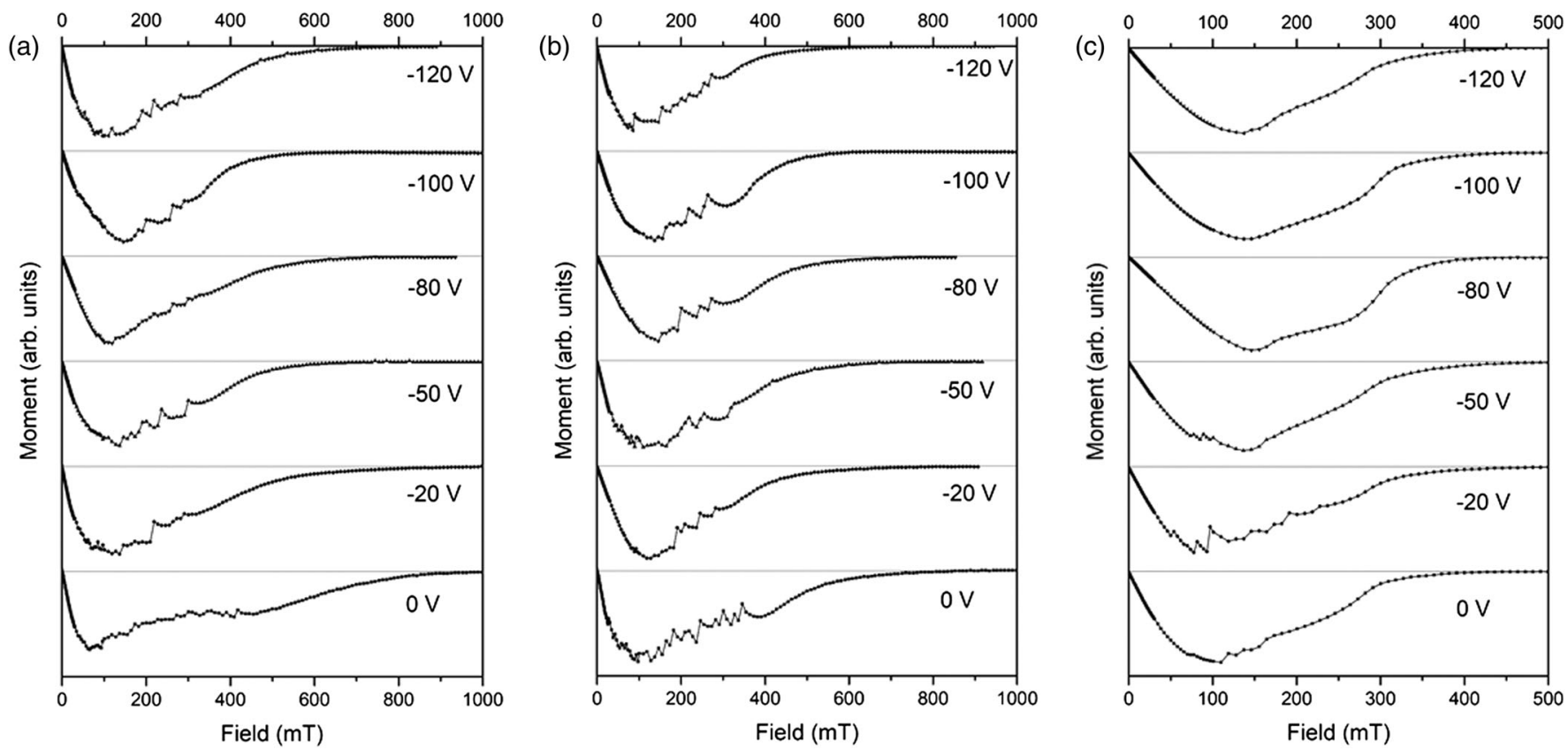

FIG. 1. de magnetic moment against applied magnetic field at $4.2 \mathrm{~K}$ for niobium samples which were deposited at (a) room temperature, (b) $500^{\circ} \mathrm{C}$ and (c) $700^{\circ} \mathrm{C}$. 


\section{B. First detection of flux entry and the second critical field}

When the sample is in the full Meissner state the magnetic moment, $\mathbf{M}_{i}$, increases linearly with the applied magnetic field, $\mathrm{H}$, and can be described as

$$
M_{i}=\beta H,
$$

where $\beta$ is proportional to the undefined sample volume.

The first detection of flux entry into a superconducting film occurs when the gradient of the hysteresis curve changes after an initial linear increase [16]. To find $\beta$ for each sample, straight fitting lines were plotted for the linear section of the hysteresis curve and any deviation from the predicted moment was calculated using the root mean squares error (RMSE) method. The RMSE is initially large $(\approx 0.00009 \mathrm{emu})$ at low field due to small signal to noise ratio, before reaching a minimum $(\approx 0.00001 \mathrm{emu})$ during the linear section of the curve, then finally continuing to increase once flux begins to enter the sample.

The field at which the magnetization curve returns to zero is equivalent to the $\mathrm{H}_{C 2}$ of a superconductor. $\mathrm{H}_{C 2}$ is reached when the magnetic field becomes large enough to extinguish superconductivity.

An example of the first detected flux entry (first deviation from linear), $\mathrm{H}_{\mathrm{dev}}$, the maximum magnetization, $\mathrm{H}\left(\mathrm{M}_{\max }\right)$, and $\mathrm{H}_{C 2}$ are shown in Fig. 2. Table I gives the calculated RMSE for the measurement shown in Fig. 2.

The error in the measured moment becomes larger when the moment is smaller, as has already been discussed, therefore the field at which the magnetization effectively reaches zero has been quoted with an error set to $\pm 10 \%$.

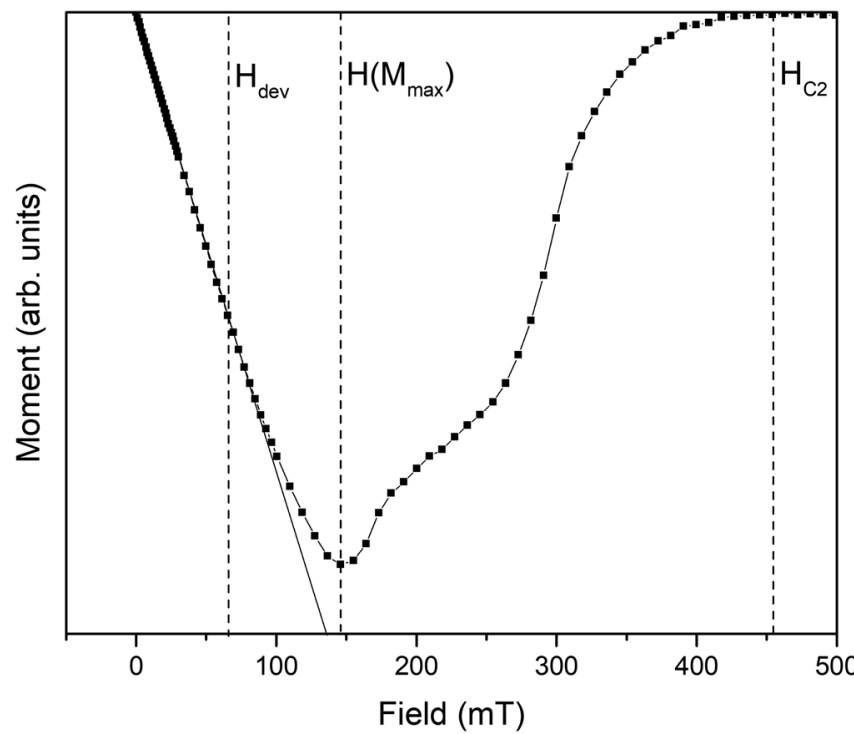

FIG. 2. Example of a raw dc hysteresis curve. The film was deposited at $700{ }^{\circ} \mathrm{C}$ with a $-80 \mathrm{~V}$ biased substrate. The dashed lines denote either $\mathrm{H}_{\mathrm{dev}}, \mathrm{H}\left(\mathrm{M}_{\max }\right)$ or $\mathrm{H}_{C 2}$.
TABLE I. Data taken from the hysteresis curve shown in Fig. 2. The RMSE begins a continuous increase at $65 \mathrm{mT}\left(\mathrm{H}_{\mathrm{dev}}\right)$ indicating that flux has already entered the sample at that field.

\begin{tabular}{lcccc}
\hline \hline $\begin{array}{l}\text { Field } \\
{[\mathrm{mT}]}\end{array}$ & $\begin{array}{c}\text { Moment } \\
{[\mathrm{emu}]}\end{array}$ & $\begin{array}{c}\text { Predicted moment } \\
{[\mathrm{emu}]}\end{array}$ & $\begin{array}{c}\text { Difference } \\
{[\mathrm{emu}]}\end{array}$ & $\begin{array}{c}\text { RMSE } \\
{[\mathrm{emu}]}\end{array}$ \\
\hline 0 & 0.00000 & -0.00009 & 0.00009 & 0.00009 \\
10 & -0.00315 & -0.00313 & -0.00002 & 0.00001 \\
20 & -0.00624 & -0.00615 & -0.00009 & 0.00002 \\
30 & -0.00931 & -0.00917 & -0.00014 & 0.00003 \\
41 & -0.01274 & -0.01265 & -0.00009 & 0.00002 \\
49 & -0.01507 & -0.01503 & -0.00005 & 0.00001 \\
61 & -0.01846 & -0.01854 & 0.00007 & 0.00001 \\
65 & $-\mathbf{0 . 0 1 9 5 2}$ & $-\mathbf{0 . 0 1 9 7 0}$ & $\mathbf{0 . 0 0 0 1 8}$ & $\mathbf{0 . 0 0 0 0 3}$ \\
69 & -0.02062 & -0.02092 & 0.00030 & 0.00005 \\
73 & -0.02172 & -0.02208 & 0.00036 & 0.00006 \\
77 & -0.02285 & -0.02328 & 0.00043 & 0.00007 \\
81 & -0.02387 & -0.02444 & 0.00057 & 0.00009 \\
85 & -0.02487 & -0.02560 & 0.00073 & 0.00011 \\
89 & -0.02591 & -0.02681 & 0.00089 & 0.00013 \\
92 & -0.02680 & -0.02795 & 0.00115 & 0.00017 \\
96 & -0.02768 & -0.02910 & 0.00142 & 0.00020 \\
100 & -0.02859 & -0.03028 & 0.00169 & 0.00024 \\
\hline \hline
\end{tabular}

Figures 3 and 4 show plots of $\mathrm{H}_{\mathrm{dev}}$ and $\mathrm{H}_{C 2}$ data respectively for all samples. $\mathrm{H}_{\mathrm{dev}}$ was at its maximum of $65 \pm 4 \mathrm{mT}$ for the sample deposited at $700^{\circ} \mathrm{C}$ with $-80 \mathrm{~V}$ biased substrate. A peak in $\mathrm{H}_{\mathrm{dev}}$ occurred at a $-80 \mathrm{~V}$ bias for all temperatures. $\mathrm{H}_{C 2}$ peaked at $1000 \mathrm{mT}$ for films deposited at room temperature without bias and with $-20 \mathrm{~V}$ bias and at $500^{\circ} \mathrm{C}$ without bias. $\mathrm{H}_{C 2}$ dropped to between 800 and $600 \mathrm{mT}$ for all other bias voltages at room temperature and $500^{\circ} \mathrm{C}$. The smallest $\mathrm{H}_{C 2}$ values were between 400 and $500 \mathrm{mT}$ and occurred for all samples

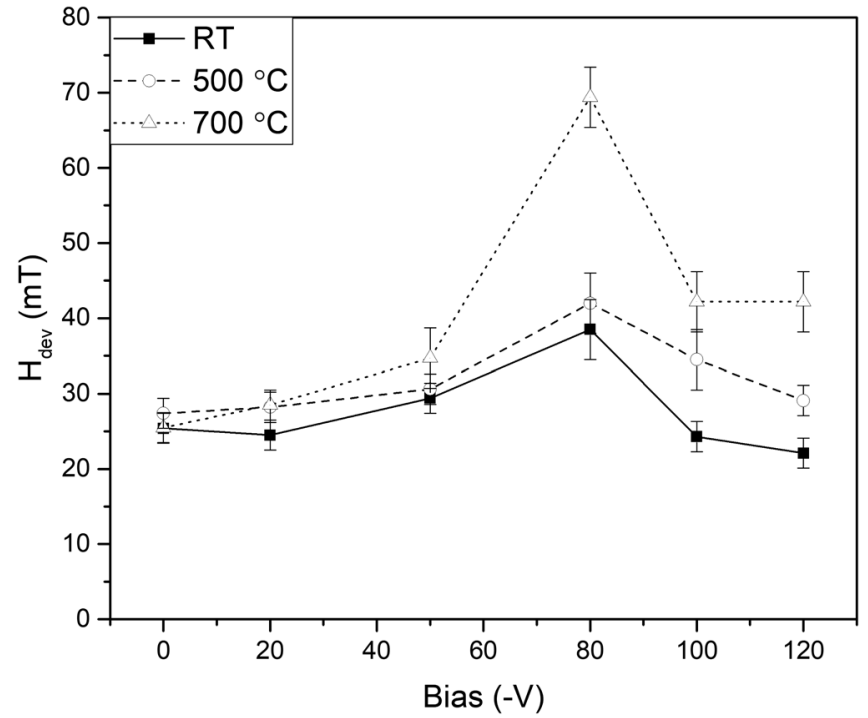

FIG. 3. The magnetic field $\mathrm{H}_{\mathrm{dev}}$ at which the gradient of the hysteresis curve first changes from linearity for each deposited film. 


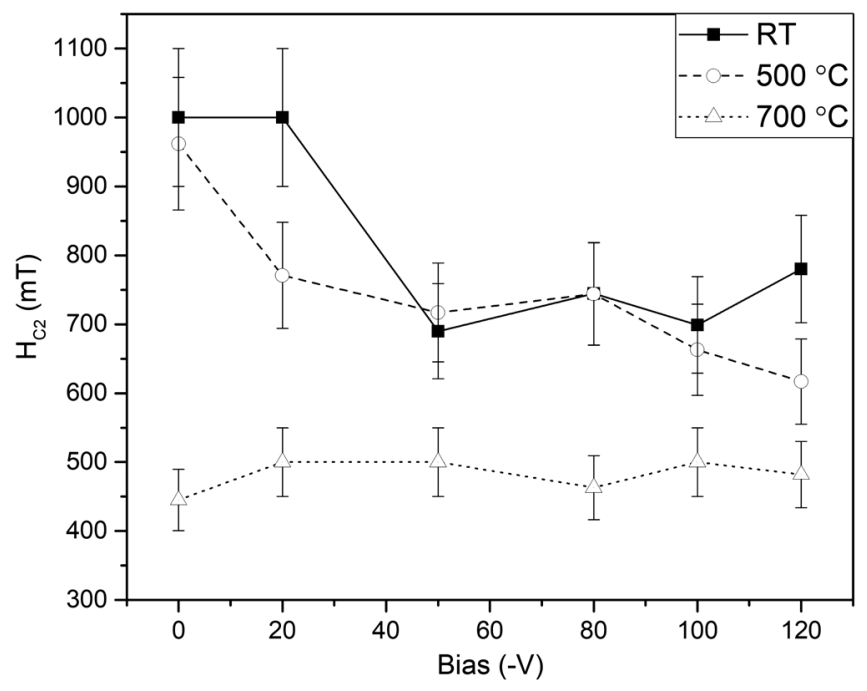

FIG. 4. The magnetic field $\mathrm{H}_{C 2}$ for each deposited film.

deposited at $700^{\circ} \mathrm{C}$. The maximum magnetization $\mathrm{H}\left(\mathrm{M}_{\max }\right)$ was recorded for each deposited film however showed no consistent trends relating to either substrate temperature or applied bias; the results are displayed in Fig. 5.

\section{Data normalization}

A simple algorithm was applied to compare all hysteresis curves. Coefficients $\beta$ allow the normalization of each set of measurements, $\mathrm{M}$, to the ideal moment, $\mathrm{M}_{i}$, of the sample if it is in the Meissner state. Thus $\mathrm{M} / \mathrm{M}_{i}=1$ corresponds to a sample in the Meissner state. Any deviation from $\mathrm{M} / \mathrm{M}_{i}=1$ will therefore be proportional to the fraction of the sample volume which is no longer in the Meissner state and contains magnetic flux, $(\Delta \mathrm{V} / \mathrm{V})_{M}$. The linear section of the raw data, where $\mathrm{M} / \mathrm{M}_{i}=1$, was defined as the

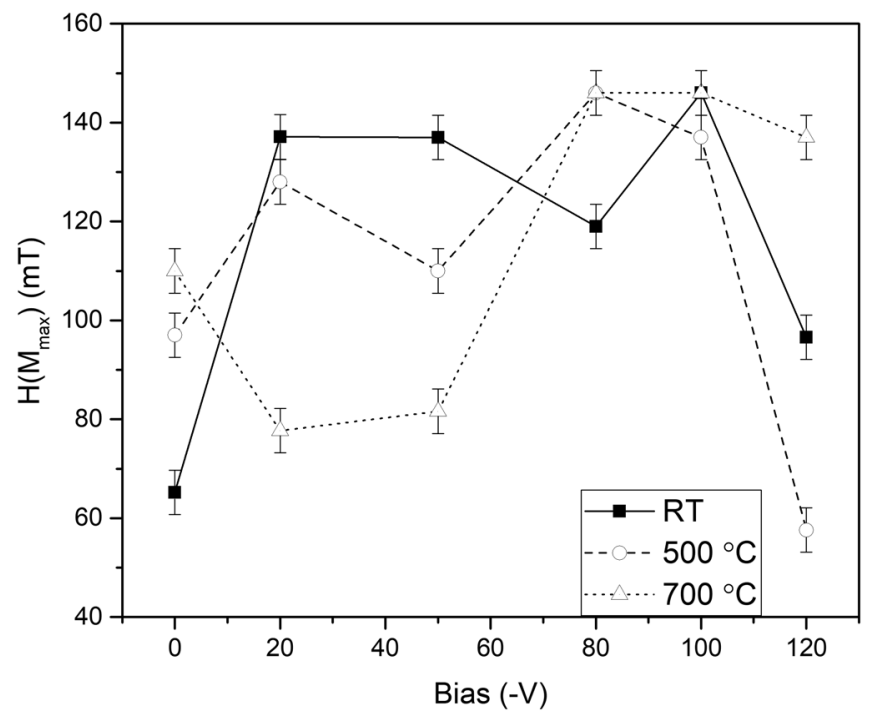

FIG. 5. The maximum recorded magnetization $\mathrm{H}\left(\mathrm{M}_{\max }\right)$ for each deposited film.

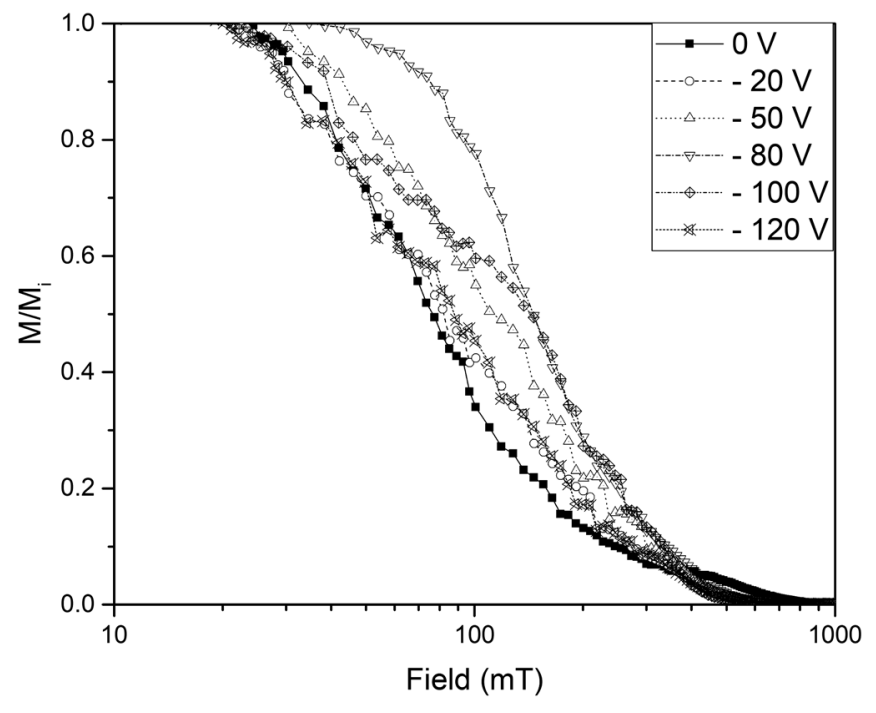

FIG. 6. The normalized dc hysteresis curves for samples deposited at room temperature with substrate bias of 0 to $-120 \mathrm{~V}$.

minimum RMSE as described for one sample in Table I. The results are shown in Figs. 6-8.

\section{Meissner state ratio}

Meissner state ratios for films deposited at room temperature are shown in Fig. 6. The film deposited at room temperature and with a $-80 \mathrm{~V}$ bias displayed $\mathrm{M} / \mathrm{M}_{i}$ which is consistently larger than for any other film up to a magnetic field of $150 \mathrm{mT}$, at which point the films biased at -80 and $-100 \mathrm{~V}$ converge. The films deposited with bias voltages of $0,-20$ and $-120 \mathrm{~V}$ display the smallest $\mathrm{M} / \mathrm{M}_{i}$ up to fields of approximately $350 \mathrm{mT}$.

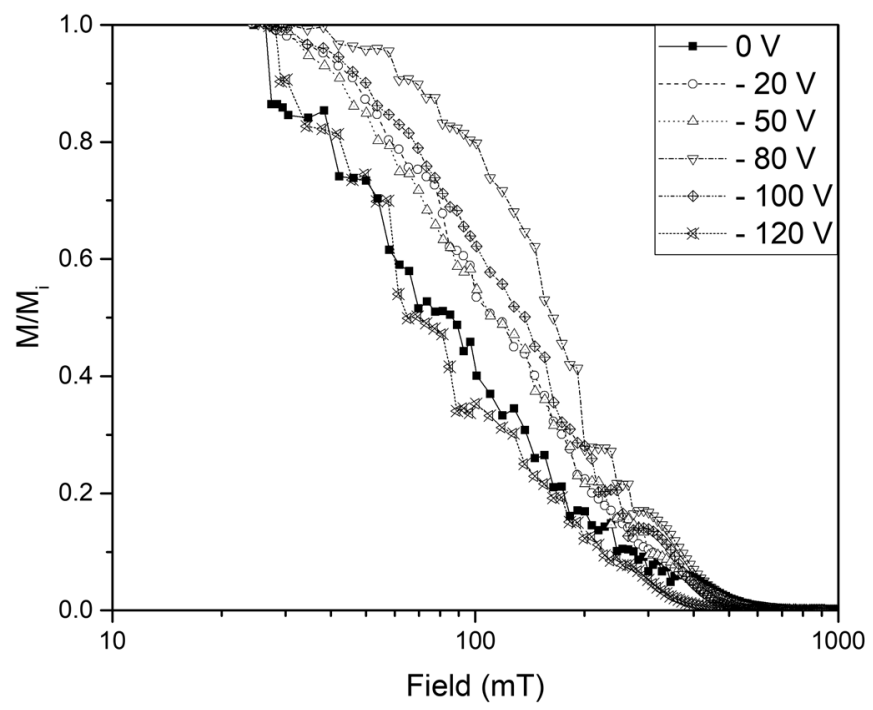

FIG. 7. The normalized dc hysteresis curves for samples deposited at $500^{\circ} \mathrm{C}$ with substrate bias of 0 to $-120 \mathrm{~V}$. 


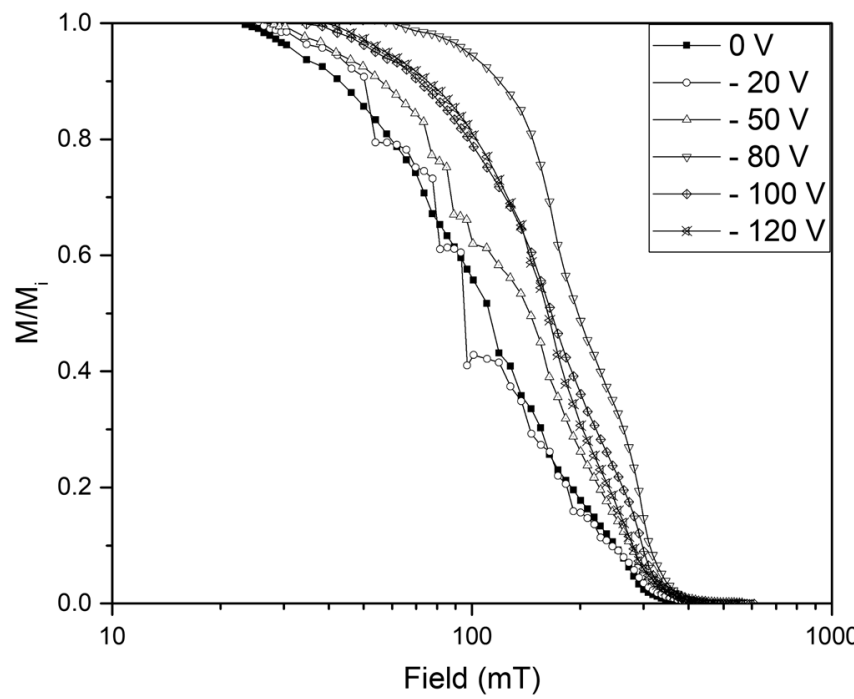

FIG. 8. The normalized dc hysteresis curves for samples deposited at $700^{\circ} \mathrm{C}$ with substrate bias of 0 to $-120 \mathrm{~V}$.
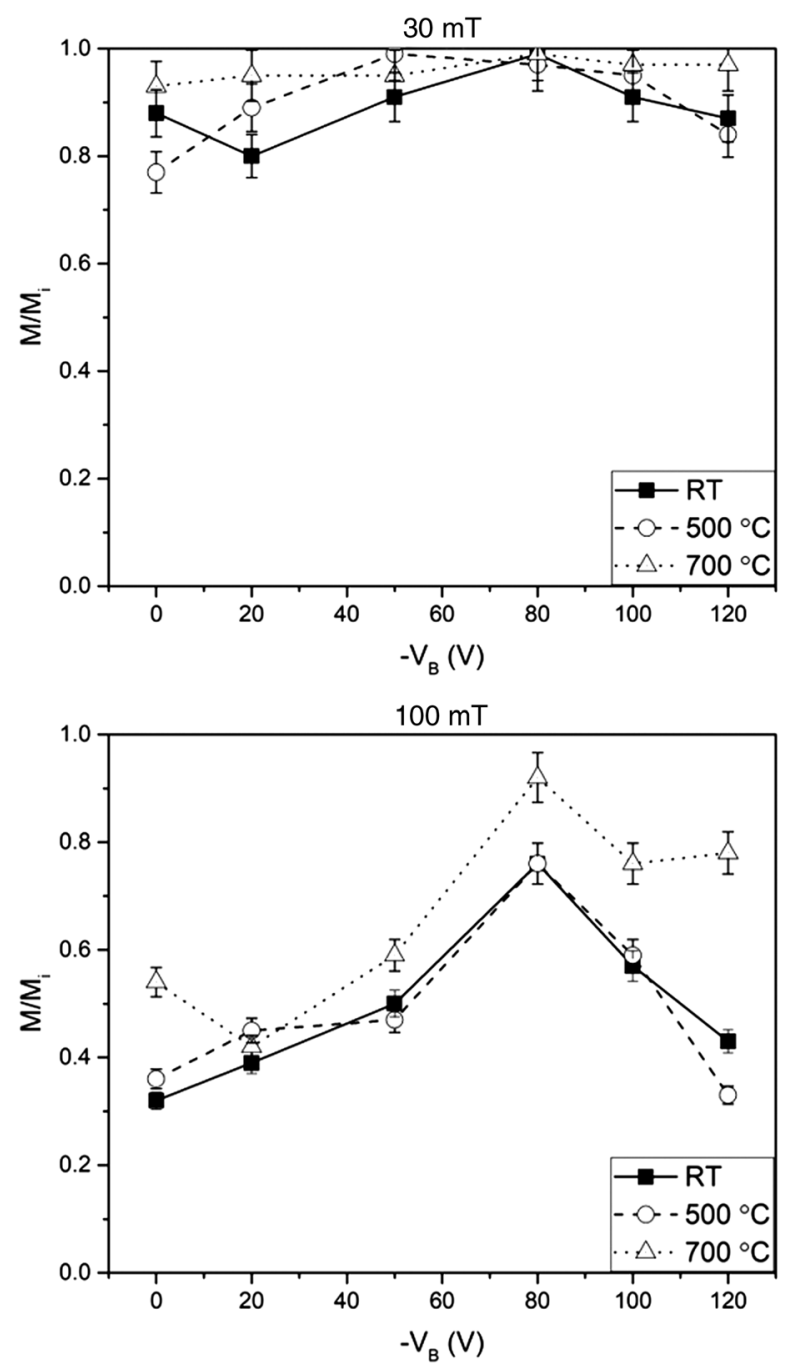

Films deposited with a substrate heated to $500^{\circ} \mathrm{C}$ are presented in Fig. 7. $\mathrm{M} / \mathrm{M}_{i}$ was largest for the film deposited with a $-80 \mathrm{~V}$ bias, displaying a similar curve to the film deposited with the same bias at room temperature. The films deposited at $500{ }^{\circ} \mathrm{C}$ without bias and with $-120 \mathrm{~V}$ bias displayed the smallest average $\mathrm{M} / \mathrm{M}_{i}$ of all films deposited at that temperature.

$\mathrm{M} / \mathrm{M}_{i}$ for all films deposited at $700^{\circ} \mathrm{C}$ are shown in Fig. 8. $M / M_{i}$ was largest for the film deposited with $-80 \mathrm{~V}$ bias and displayed the sharpest transition from the Meissner state to $\mathrm{H}_{C 2}$ of any films deposited during the study. $\mathrm{M} / \mathrm{M}_{i}$ for the films deposited at -100 and $-120 \mathrm{~V}$ displayed very similar properties over the entire curve. The smallest $\mathrm{M} / \mathrm{M}_{i}$ was observed for the films deposited with bias voltages of either 0 or $-20 \mathrm{~V}$.

Figure 9 illustrates all deposited samples together at magnetic fields of 30,60, 100 and $180 \mathrm{mT}$. All films achieved an $\mathrm{M} / \mathrm{M}_{i}$ above 0.8 at $30 \mathrm{mT} . \mathrm{M} / \mathrm{M}_{i}$ is largest at
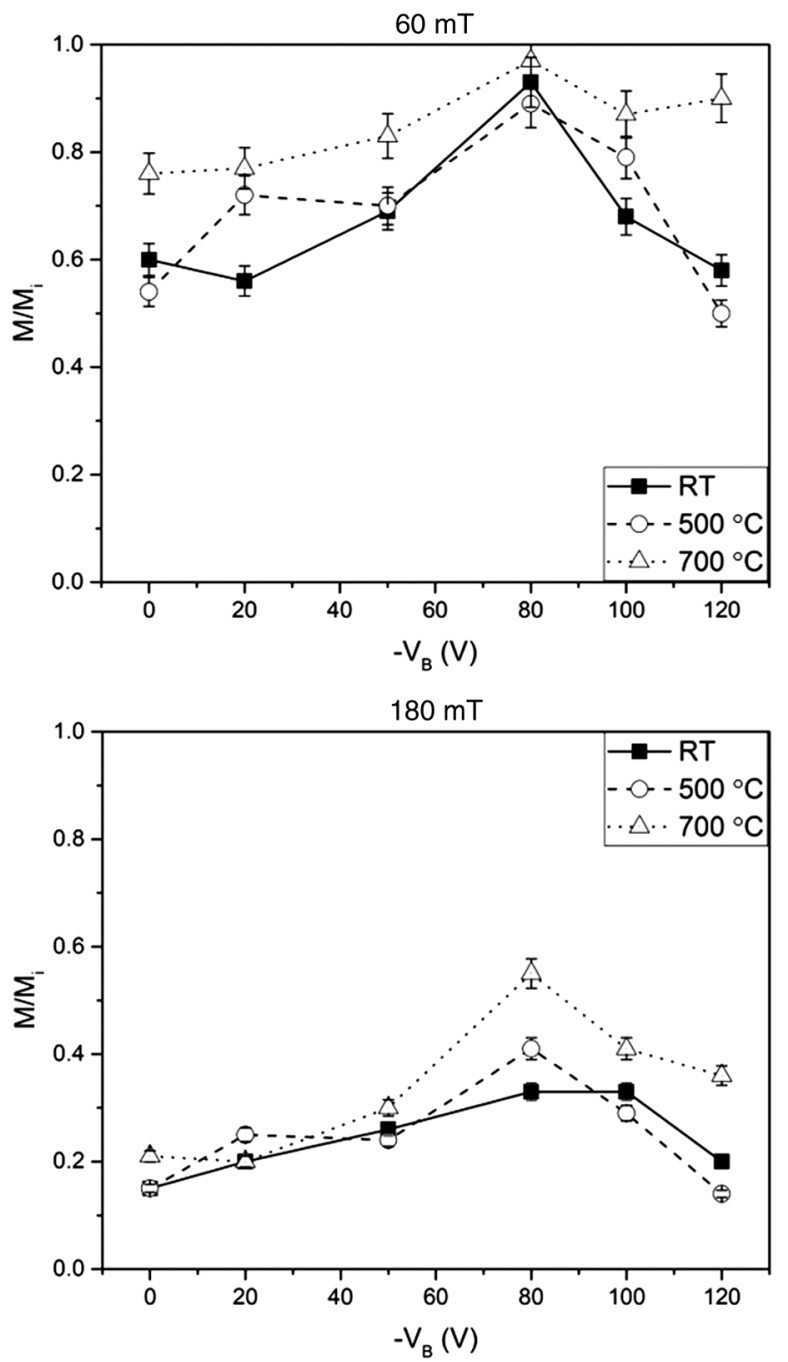

FIG. 9. Compilation of the measured $\mathrm{M} / \mathrm{M}_{i}$ for every sample at magnetic fields of 30, 60, 100 and $180 \mathrm{mT}$. The bias voltage applied to each sample is denoted as $-\mathrm{V}_{B}(\mathrm{~V})$. 
bias voltages of -50 to $-100 \mathrm{~V}$ for all temperatures at $30 \mathrm{mT}$.

A distinct peak occurs at $-80 \mathrm{~V}$ bias for films deposited at room temperature, $500^{\circ} \mathrm{C}$ and $700^{\circ} \mathrm{C}$ with an applied field strength of $60 \mathrm{mT}$. The shape of the $\mathrm{M} / \mathrm{M}_{i}$ curve is similar for $500^{\circ} \mathrm{C}$ and $700^{\circ} \mathrm{C}$ at bias voltages of -20 to $-100 \mathrm{~V}$ however the $\mathrm{M} / \mathrm{M}_{i}$ for room temperature films deposited at -20 and $-100 \mathrm{~V}$ is relatively smaller. $\mathrm{M} / \mathrm{M}_{i}$ is larger at $700{ }^{\circ} \mathrm{C}$ relative to both room temperature and $500{ }^{\circ} \mathrm{C}$ for the unbiased samples and those biased at -50 and $-120 \mathrm{~V}$.

Within the error margins, $\mathrm{M} / \mathrm{M}_{i}$ is the same at each bias voltage for room temperature and $500^{\circ} \mathrm{C}$ films at $100 \mathrm{mT}$, exhibiting a peak at $-80 \mathrm{~V}$. $\mathrm{M} / \mathrm{M}_{i}$ for films deposited at $700^{\circ} \mathrm{C}$ has become greatly enhanced relative to room temperature and $500^{\circ} \mathrm{C}$ for the unbiased films and bias voltages of -80 to $-120 \mathrm{~V}$.

$\mathrm{M} / \mathrm{M}_{i}$ is no larger than 0.55 for any film at $180 \mathrm{mT}$ and a peak can still be observed at $-80 \mathrm{~V}$ for all temperatures.

\section{E. RRR}

RRR for each deposited film is shown in Fig. 10. The smallest RRR values of 9 were measured for the films deposited at room temperature and $500^{\circ} \mathrm{C}$ without an applied bias voltage. RRR peaked at 19 to 21 for the films deposited at room temperature with bias voltages of -50 to $-120 \mathrm{~V}$. RRR peaked at 29 to 31 for the films deposited at $500^{\circ} \mathrm{C}$ with bias voltages of -20 to $-80 \mathrm{~V}$. The largest RRR values of between 52 and 54 occurred at a substrate temperature of $700^{\circ} \mathrm{C}$ with bias voltages of $0,-50,-80$ and $-120 \mathrm{~V}$ with slightly smaller values of 43 and 42 for the -20 and $-100 \mathrm{~V}$ biased samples, respectively.

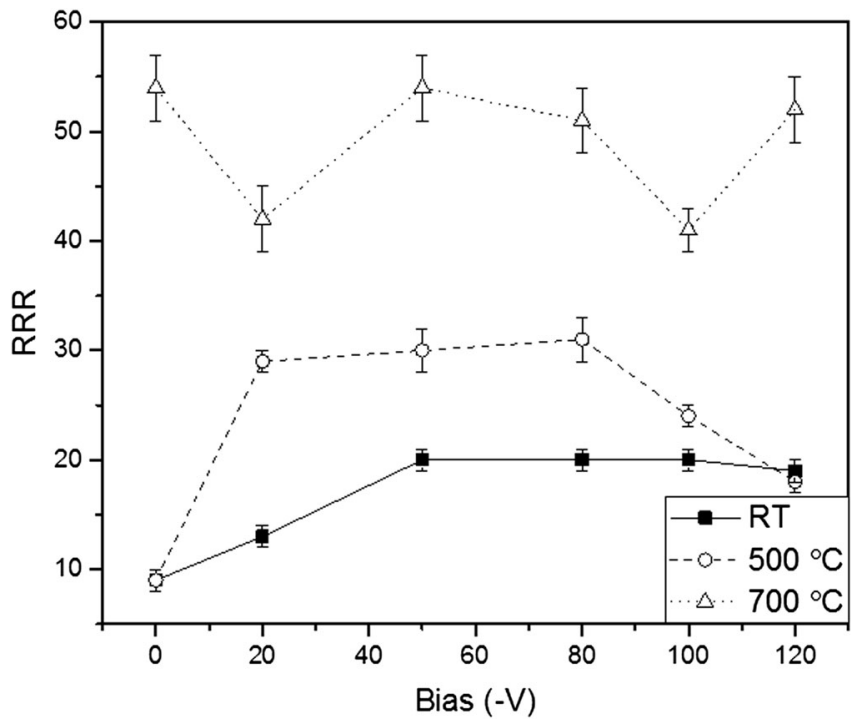

FIG. 10. RRR of niobium thin films deposited with substrate temperature ranging from room temperature to $700^{\circ} \mathrm{C}$ and with dc bias voltages ranging 0 to $-120 \mathrm{~V}$.

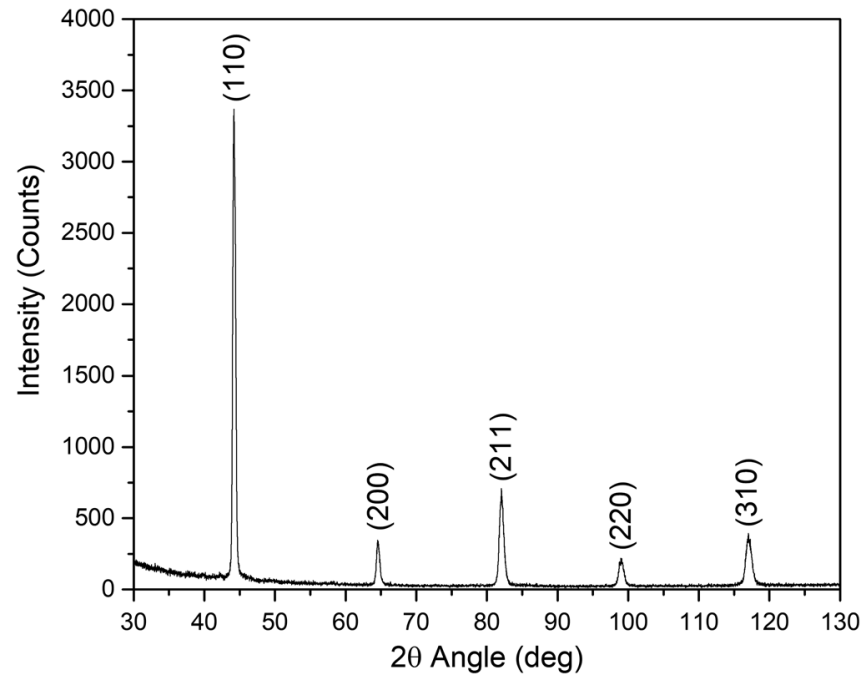

FIG. 11. GI-XRD measurement of a niobium thin film sample after the copper substrate had first been etched away. The sample was originally deposited at a substrate temperature of $700^{\circ} \mathrm{C}$ with $-80 \mathrm{~V}$ substrate bias.

\section{F. Lattice parameters and surface imaging}

All deposited samples grew with the same body centered cubic structure with preferred (110) growth orientation corresponding to a peak at approximately $44^{\circ}$ to $45^{\circ}$. Small peaks relating to the (200), (211), (210) and (310) orientations were also observed in every deposited film. A typical GI-XRD measurement is shown in Fig. 11. The film was deposited at $700^{\circ} \mathrm{C}$ with $-80 \mathrm{~V}$ biased substrate during deposition and the substrate had been etched away before the GI-XRD measurement was performed.

The lattice parameters of all deposited films are shown in Fig. 12. The samples with the copper substrate etched away display similar lattice parameters of 3.31 to $3.33 \AA$ for films deposited at room temperature with bias voltages of 0 to $-100 \mathrm{~V}$ and at $500^{\circ} \mathrm{C}$ with bias voltages of $0,-50,-80$, -100 and $-120 \mathrm{~V}$. The film deposited at $-120 \mathrm{~V}$ at room temperature exhibits a large lattice parameter at $3.37 \AA$ and the film deposited at $500^{\circ} \mathrm{C}$ with $-20 \mathrm{~V}$ bias a small lattice parameter of $3.26 \AA$. The lattice parameters of films deposited at $700^{\circ} \mathrm{C}$ are larger than at room temperature and $500^{\circ} \mathrm{C}$. The film biased at $-120 \mathrm{~V}$ at $700^{\circ} \mathrm{C}$ has the largest lattice parameter of all films at 3.38 whilst all other films deposited at that temperature range 3.35 to $3.36 \AA$.

The lattice parameters of the films with the copper substrate still in place are different from those with the substrate etched away. Films measured on copper that were deposited at room temperature show little variation in lattice parameter with all bias voltages ranging from 3.27 to $3.30 \AA$. The lattice parameter of the films deposited at $500^{\circ} \mathrm{C}$ and $700^{\circ} \mathrm{C}$ with bias voltages of 0 and $-20 \mathrm{~V}$ have larger lattice parameters than was displayed at room temperature whilst the lattice parameter of the sample deposited at $500^{\circ} \mathrm{C}$ with $-120 \mathrm{~V}$ is smaller. The lattice 

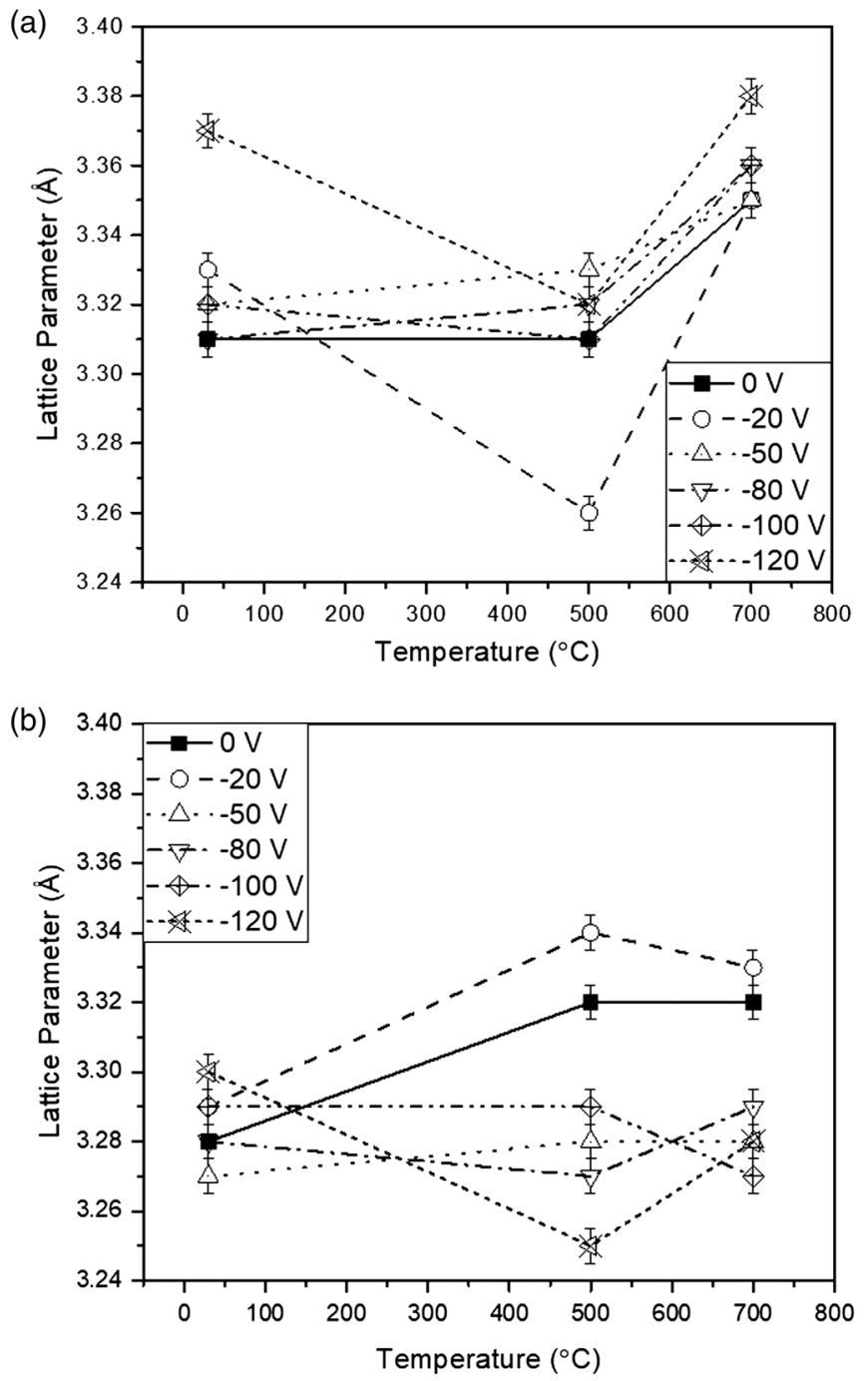

FIG. 12. The calculated lattice parameters of niobium thin films deposited at either room temperature, $500^{\circ} \mathrm{C}$ or $700^{\circ} \mathrm{C}$ with bias voltages of $0,-20,-50,-80,-100$ or $-120 \mathrm{~V}$ with (a) the copper substrate removed by etching or (b) with the copper substrate still in place.

parameters of the films deposited at $500^{\circ} \mathrm{C}$ and $700^{\circ} \mathrm{C}$ with bias voltages of -50 to $-100 \mathrm{~V}$ are comparable to those which were measured for films deposited at room temperature with similar bias voltage.

Planar SEM images of the films deposited at either 0 or $-80 \mathrm{~V}$ bias for each of the three temperatures considered are shown in Fig. 13. The films deposited at room temperature and $500^{\circ} \mathrm{C}$ without an applied substrate bias grow with columnar grains whereas those deposited at $-80 \mathrm{~V}$ bias appear to have grains which are more densely packed together. Grain sizes of all films deposited at room temperature and $500^{\circ} \mathrm{C}$ appear to be of the order of submicrons; however, grain size does appear slightly enhanced at the larger substrate temperature. The visible grain structure of films deposited at $700^{\circ} \mathrm{C}$ do not display significant changes from the unbiased sample and that biased at $-80 \mathrm{~V}$. Grains
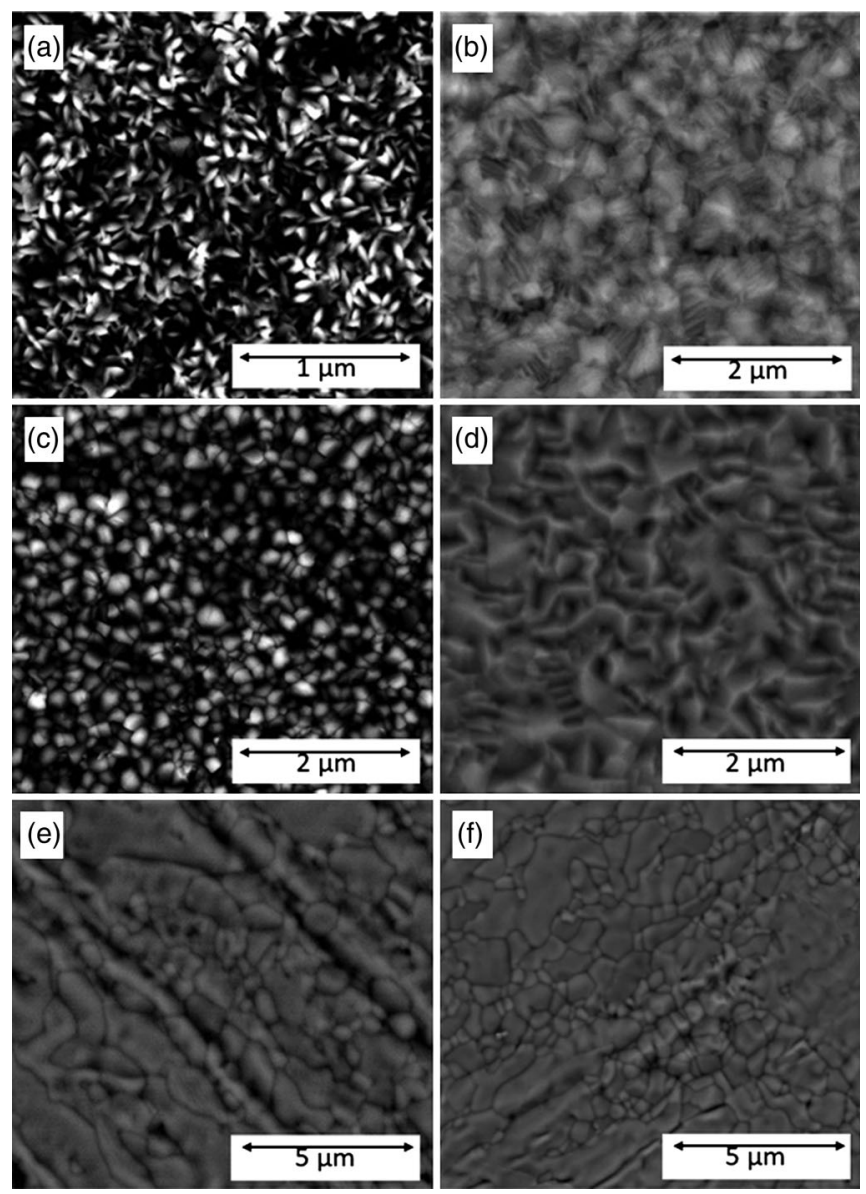

FIG. 13. Planar SEM images of niobium thin film samples deposited (a) at room temperature and no bias, (b) at room temperature with $-80 \mathrm{~V}$ bias, (c) at $500^{\circ} \mathrm{C}$ with no bias, (d) at $500^{\circ} \mathrm{C}$ and $-80 \mathrm{~V}$ bias, (e) at $700^{\circ} \mathrm{C}$ with no bias and (f) at $700^{\circ} \mathrm{C}$ with $-80 \mathrm{~V}$ bias.

have grown much larger at $700^{\circ} \mathrm{C}$ relative to room temperature and $500^{\circ} \mathrm{C}$ with grains of up to approximately 4-5 microns across.

\section{DISCUSSION}

The interpretation of the dc magnetic hysteresis measurements is perfectly valid and unambiguous only for cases when the thin film investigated is parallel to the applied magnetic field. Indeed, the magnetic behavior of superconducting thin films can be very different for samples which are aligned perfectly with the field and for films which are inclined to the magnetic field. Superconducting quantum interference device measurement of superconducting films with $\mathrm{H}$ parallel to the sample plane is fairly difficult to analyze because of the existence of a strong transverse signal, as shown in [17]. Moreover, regardless of any sample anisotropy, a purely geometric effect is to be expected due to edge effects. The magnetic moment is very sensitive to any small disorientation of the sample, which will have a dramatic effect on 


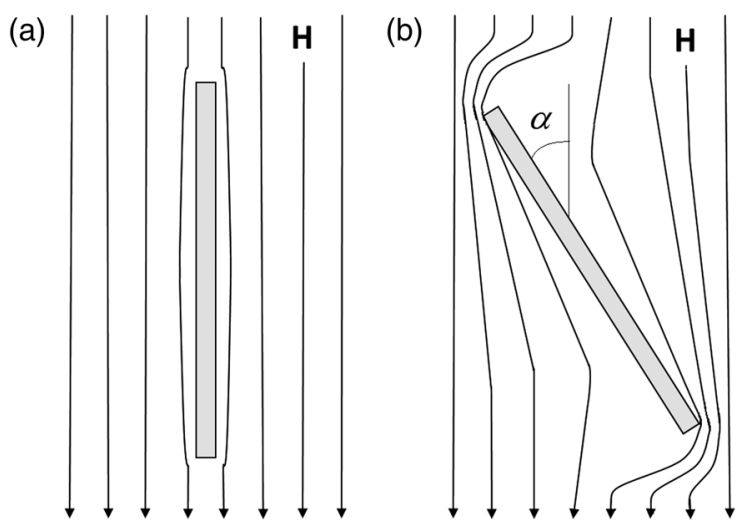

FIG. 14. Schematic representation of magnetic field lines for (a) superconducting sample parallel to the applied magnetic field lines and (b) superconducting sample inclined with angle $\alpha$.

the signal intensity. Figure 14 illustrates a superconducting thin film oriented either parallel or inclined to the applied magnetic field. The area of samples which are perpendicular to the applied magnetic field is equal to $A \sin \alpha$. Therefore, the superconducting thin film ideally positioned parallel to the magnetic field will interfere much less than a thin film placed with an angle, $\alpha>0$. The film can be considered parallel to the magnetic field if $\alpha<\mathrm{d} / \mathrm{L}$. We can use Eq. (4) to approximate an upper limit for $\alpha$ in the parallel orientation to be $0.2 \mathrm{mrad}$, assuming a film thickness of $1 \mu \mathrm{m}$ and length of $5 \mathrm{~mm}$ :

$$
\alpha(\mathrm{rad}) \approx \frac{d}{L} \approx \frac{1 \mu \mathrm{m}}{5000 \mu \mathrm{m}} \approx 0.2 \mathrm{mrad}
$$

The value of $0.2 \mathrm{mrad}$ is much smaller than the error in sample alignment of $\pm 17 \mathrm{mrad}$ therefore samples in our experiment cannot be considered parallel to the magnetic field. If the sample is not perfectly parallel to the magnetic field, then the magnetic field near the edges is enhanced with respect to the rest of the sample. Thus, the magnetic field penetrates early into the edges of the sample, whilst the rest of the sample remains in the Meissner state.

The limitations of the sample alignment dictate that it is difficult to separate the two phenomena of flux penetration due to edge effects and flux penetration due to whole sample properties.

Multiple flux jumps were observed in Figs. 1(a) and 1(b) for all films deposited at room temperature and $500^{\circ} \mathrm{C}$ and in Fig. 1(c) for a selection of films deposited at $700^{\circ} \mathrm{C}$. Such flux jumps represent unstable flux pinning and rapid reorientation of vortices into more energetically stable pinning locations as the magnetic field strength changes [18]. In extreme cases of multiple flux jumps it can lead to the so-called vortex avalanches [19]. Types of pinning locations are precipitates of nonsuperconducting material, precipitates of superconducting material with reduced transition temperature, lattice dislocations, interplanar defects or grain boundaries. Vortices which move between pinning locations act as a viscous fluid and can produce areas of local heating which in turn can promote Cooper pair breaking. Enhanced numbers of unpaired electrons will increase the possibility of a quench [20]. Superconductors which display stable flux pinning are likely to have better thermal conductivity than superconductors which exhibit unstable flux pinning.

A range of films was deposited and tested multiple times and the results showed that the sample to sample variation in $\mathrm{M} / \mathrm{M}_{i}$ was highly repeatable for samples which did not exhibit flux jumps, but the measured moment could fluctuate about the approximate magnitude of the flux jumps for those which did exhibit jumps. Samples which demonstrate either no jumps or one or two jumps show the highest average $\mathrm{M} / \mathrm{M}_{i}$ values over the range of between $60 \mathrm{mT}$ and $\mathrm{H}_{C 2}$. The films which showed the least flux jumps were the $700^{\circ} \mathrm{C}$ films with bias voltages of -80 to $-120 \mathrm{~V}$. This would indicate that either a minimum amount of energy must be supplied to the growing film to reduce the defect density to a level which is required for stable flux pinning, or changes occur within the substrate at $700^{\circ} \mathrm{C}$, such as growth of grains or removal of the surface oxide layer, which could promote the growth of films that can exhibit stable flux pinning. Studies have in fact already shown that the substrate condition can greatly affect the properties of niobium films [4], where oxide-free copper surfaces, as would be expected at $700^{\circ} \mathrm{C}$, produced much larger grain size than films grown onto the native oxide of copper. The morphological characterization of our films confirmed that both grain size and RRR was much larger for films deposited at $700^{\circ} \mathrm{C}$ when compared to the lower temperatures.

The field at which the gradient first changes for each hysteresis curve indicates the first detectable change in the magnetic properties of the sample and is therefore the first detectable sign of flux entry into a sample. The results indicate that no film remained in the Meissner state above $65 \mathrm{mT}$ which is well below the $\mathrm{H}_{\mathrm{SH}}$ of niobium, at $220 \mathrm{mT}$. The early flux penetration occurred due to the sample geometry within the applied magnetic field which produces the edge effects.

Results describe an enhancement in the field where the first flux penetration can be detected within sample films which were deposited with a $-80 \mathrm{~V}$ bias at all temperatures. The gradual increase in $\mathrm{H}_{\mathrm{dev}}$ from no bias to $-80 \mathrm{~V}$ bias and subsequent reduction in $\mathrm{H}_{\mathrm{dev}}$ at higher bias voltages can be explained using well-known thin film growth theory [15]. Films with relatively few defects will be deposited if the transferred energy due to ion bombardment is above the surface displacement energy but below the bulk displacement energy of niobium [21]. The initial application of a bias voltage will accelerate charged ions towards the substrate and so promote the breaking of 
atomic bonds at the films surface. Ion bombardment then increases surface atom mobility and diffusion whilst also annihilating surface defects. The rate of surface diffusion rises with increased bias voltage, further reducing defect densities up to the threshold of $-80 \mathrm{~V}$. The images of the surface of the samples show how the films deposited at room temperature and $500^{\circ} \mathrm{C}$ change from columnar films deposited with a grounded substrate to more densely packed grains with a bias of $-80 \mathrm{~V}$. Reduced $\mathrm{H}_{\mathrm{dev}}$ at -100 and $-120 \mathrm{~V}$ then suggests that high energy ion bombardment produces more defects than are being annihilated. The types of defect which are produced by high energy bombardment can be both a reduction in grain size (more grain boundaries) and random complex dislocations. $\mathrm{H}_{\text {dev }}$ increases with temperature for bias voltages of -100 and $-120 \mathrm{~V}$ where the heat energy enhances the probability of annealing out defects within the film and reduces the volume of grain boundaries.

The RRR results for samples deposited at $500^{\circ} \mathrm{C}$ display an increase from 0 to $-80 \mathrm{~V}$, then a drop at -100 and $-120 \mathrm{~V}$ and was like observations of $\mathrm{H}_{\mathrm{dev}}$. The same drop in RRR was not seen for films deposited at room temperature with bias voltages of -100 and $-120 \mathrm{~V}$; however, RRR rose from 9 without bias to a plateau of between 19 and 21 with biases of -50 to $-120 \mathrm{~V}$ indicating there is a finite limit to the improvement in crystallinity as the bias is increased. The slight inconsistency between observations of $\mathrm{RRR}$ and $\mathrm{H}_{\mathrm{dev}}$ for films deposited at room temperature with biases of -100 and $-120 \mathrm{~V}$ supports the theory that more random complex defects can form within a deposited film as the ion energy is increased past a certain threshold. RRR is consistently large at $700^{\circ} \mathrm{C}$ and results from the dramatic enlargement of grain size when compared to films deposited at room temperature and $500^{\circ} \mathrm{C}$, with and without an applied bias.

The lattice parameters give an idea of the nature of the defects which may be present within films. Lattice parameters were different in every instance for films measured on copper relative to those which had been etched, indicating that the substrate has a large influence on the stresses within a growing film. Bias voltages of -50 to $-100 \mathrm{~V}$ display consistent values between 3.27 and $3.29 \AA$ for each temperature when measured on the copper substrate. The lattice parameters of etched films with bias voltage of -50 to $-100 \mathrm{~V}$ are still consistent with each other, however slightly larger when compared to those of the films measured on copper, and are largest for the films deposited at $700^{\circ} \mathrm{C}$. A consistency of the lattice parameter indicates a consistency in the types of defect present in the film microstructure and is likely determined by either the densities of grain boundaries or impurity atoms. However, seemingly random distributions of the lattice parameter are most likely caused by the presence of random complex dislocations. The lattice parameter for the $-120 \mathrm{~V}$ biased films varies widely as the deposition temperature changes from room temperature up to $700^{\circ} \mathrm{C}$ for both the films measured on copper and after it was etched. The inconsistent and varying lattice parameters of the films deposited with $-120 \mathrm{~V}$ bias strengthen the argument that random defects are produced at high bias voltage, as discussed for the $\mathrm{H}_{\mathrm{dev}}$ and $\mathrm{RRR}$ results. The lattice parameter of the films deposited with both 0 and $-20 \mathrm{~V}$ bias displays much larger values at 500 and $700^{\circ} \mathrm{C}$ than for the other tested bias voltages when measured on copper and there was a relatively small lattice parameter displayed by the etched film deposited with $-20 \mathrm{~V}$ bias at $500^{\circ} \mathrm{C}$. The inconsistencies in lattice parameter for films deposited with either no bias or very small bias indicate that random defects are frequent within these films as the energy of bombarding ions was not high enough to annihilate them.

The films deposited at room temperature and $500^{\circ} \mathrm{C}$ without substrate bias display similar $\mathrm{H}_{C 2}$ of $1000 \mathrm{mT} . \mathrm{H}_{C 2}$ then drops at either room temperature with bias voltages of $-50 \mathrm{~V}$ or larger or at $500^{\circ} \mathrm{C}$ with bias voltages of $-20 \mathrm{~V}$ or larger, to a minimum value of $617 \mathrm{mT}$. $\mathrm{H}_{C 2}$ is consistently smaller for a deposition temperature of $700^{\circ} \mathrm{C}$ at between 400 and $500 \mathrm{mT}$ for all bias voltages. The results suggest that $\mathrm{H}_{C 2}$ is determined by the defect and impurity densities within films which act as magnetic pinning centers, especially those found at grain boundaries. The samples with the largest $\mathrm{H}_{C 2}$ of $1000 \mathrm{mT}$ coincide with the three films which had the smallest RRR, between 9 and 13, of all the deposited samples. $\mathrm{H}_{C 2}$ was then smaller for the films which had larger RRR at room temperature and $500^{\circ} \mathrm{C}$. A consistently small $\mathrm{H}_{C 2}$ was measured for the films deposited at $700^{\circ} \mathrm{C}$ where grain size and RRR were largest.

$\mathrm{M} / \mathrm{M}_{i}$ is proportional to the fraction of the sample volume which contains magnetic vortices and gives an alternative description of the behavior of the flux entry into the sample. Films which have the largest $\mathrm{M} / \mathrm{M}_{i}$ can be assumed to be more resistant to penetration by an applied magnetic field. Samples which show the largest $\mathrm{M} / \mathrm{M}_{i}$ relative to the applied field strength are therefore good candidates for further rf testing as they have a smaller percentage volume which contains pinned magnetic vortices. Pinned magnetic vortices oscillate within rf electric fields and lead to dissipative heating and ultimately a cavity quench when used in SRF application [22].

The $\mathrm{M} / \mathrm{M}_{i}$ curves describe little difference between deposited films at fields of $30 \mathrm{mT}$; however, differences can be observed once the field reaches $60 \mathrm{mT}$. A pattern emerges where films deposited at each temperature show a minimum volume containing magnetic flux for films with a bias voltage at $-80 \mathrm{~V}$.

A more distinct pattern can be observed at the higher field of $100 \mathrm{mT}$. The ratio of $\mathrm{M} / \mathrm{M}_{i}$ is the same within the bounds of error for room temperature and $500^{\circ} \mathrm{C}$ films for every bias voltage. The $700^{\circ} \mathrm{C}$ films developed a broad $\mathrm{M} / \mathrm{M}_{i}$ peak which covers a range of bias voltages at $100 \mathrm{mT}$. 
The same thin film growth mechanisms described in detail for the observations of $\mathrm{H}_{\mathrm{dev}}$, RRR and lattice parameter also apply for the $\mathrm{M} / \mathrm{M}_{i}$ curves. The application of a bias will initially reduce defect densities before high energy ion bombardment produces more defects than are being annihilated. The effects of substrate heating become noticeable at $700^{\circ} \mathrm{C}$ with enhanced $\mathrm{M} / \mathrm{M}_{i}$ for a broad range of bias voltages. Again, as discussed in detail earlier for results of $\mathrm{H}_{\mathrm{dev}}$, RRR and the SEM images, the higher substrate temperature reduces the volume of defects found at grain boundaries and enhances the probability of annealing out defects which occur due to high energy ion bombardment. Ideally, the experiment would use much higher temperatures to further anneal complex defects from films; however, the maximum deposition temperature is restricted by the melting temperature of $1085^{\circ} \mathrm{C}$ for the copper substrate. Thin film growth dynamics which occur at the interface between film and substrate are less predictable once the deposition temperature gets close to the melting temperature of the substrate.

It is important to note that, although our results are very important to understand the physics related to dc magnetic fields penetration in thin films deposited by HiPIMS they may not be directly extrapolated to thin film SRF cavities which are subjected to varying rf magnetic fields. Another significant difference is that the parallel magnetic field in rf cavities is applied to one side of the film only, whereas the magnetic field is applied to all sides of the sample in our dc magnetometer measurements. Further experiments are required to properly link both the $\mathrm{dc}$ and $\mathrm{rf}$ magnetic behaviors of superconducting thin films.

It should also be made clear that the results presented here are for films deposited by HiPIMS using specific process conditions. The HiPIMS power supply was set to pulse with a repetition rate of $200 \mathrm{~Hz}$, with a pulse length of $100 \mu \mathrm{s}$ and with an average current of $600 \mathrm{~mA}$. Different HiPIMS settings and other deposition techniques may yield different results.

\section{CONCLUSIONS}

The effects of substrate heating and applied bias during HiPIMS deposition on niobium thin film superconducting properties were tested using dc squid magnetometry. Films were later analyzed for RRR, lattice parameter and imaged by SEM so that the dc magnetometry results could be interpreted.

The values of $\mathrm{M} / \mathrm{M}_{i}$ for both room temperature and $500^{\circ} \mathrm{C}$ films remained constant for similar bias voltages therefore demonstrating that the applied bias had a more significant effect on the growing film than the substrate heating had up to $500^{\circ} \mathrm{C}$. The increased $\mathrm{M} / \mathrm{M}_{i}$ at $-80 \mathrm{~V}$ is expected to be a result of increased rates of surface diffusion and defect annihilation due to ion bombardment. The measured lattice parameters and correlations to RRR measurements suggest that ion bombardment has become too energetic at bias voltages of $-120 \mathrm{~V}$ and therefore more random complex defects are produced than are removed from the niobium lattice.

Average increases of $\mathrm{M} / \mathrm{M}_{i}$ for films deposited at $700^{\circ} \mathrm{C}$ relative to room temperature and $500^{\circ} \mathrm{C}$ reveal that the energy contribution towards diffusion within and at the surface of the film has become significant. There is a broad range of bias voltage which produces large $\mathrm{M} / \mathrm{M}_{i}$ at $700^{\circ} \mathrm{C}$ suggesting that there is less dependence on the applied bias at larger temperatures. RRR was also observed to be consistently larger for films deposited at $700^{\circ} \mathrm{C}$ than for room temperature and $500^{\circ} \mathrm{C}$. The most likely cause of the enhancement of $\mathrm{M} / \mathrm{M}_{i}$ and RRR at $700^{\circ} \mathrm{C}$ is the enlargement of the niobium grain size as shown in SEM images.

Samples deposited at $700^{\circ} \mathrm{C}$ exhibit smaller $\mathrm{H}_{C 2}$ than samples deposited at room temperature and $500^{\circ} \mathrm{C}$ and is most likely due to the increase in grain size.

The study concluded that the films which are most suitable for SRF applications are those deposited with a $-80 \mathrm{~V}$ substrate bias at room temperature, $500^{\circ} \mathrm{C}$ and $700^{\circ} \mathrm{C}$ as these films display similarly large $\mathrm{M} / \mathrm{M}_{i}$.

[1] R. L. Geng, H. Padamsee, A. Seaman, and V. D. Shemelin, World record accelerating gradient achieved in a superconducting niobium rf cavity, in Proceedings of the 21st Particle Accelerator Conference, Knoxville, TN, 2005 (IEEE, Piscataway, NJ, 2005).

[2] A. Grassellino, A. Romanenko, D. Sergatskov, O. Melnychuk, Y. Trenikhina, A. Crawford, A. Rowe, M. Wong, T. Khabilboulline, and F. Barkov, Nitrogen and argon doping of niobium for superconducting radio frequency cavities: A pathway to highly efficient accelerating structures, Supercond. Sci. Technol. 26, 102001 (2013).

[3] V. Arbert-Engels, C. Benvenuti, S. Calatroni, P. Darriulat, M. A. Peck, A. M. Valente, and C. A. Van't Hof, Superconducting niobium cavities, a case for the film technology, Nucl. Instrum. Methods Phys. Res., Sect. A 463, 1 (2001).

[4] C. Benvenuti, S. Calatroni, I. E. Campisi, P. Darriulat, M. A. Peck, R. Russo, and A. M. Valente, Study of the surface resistance of superconducting niobium films at $1.5 \mathrm{GHz}$, Physica C (Amsterdam) 316, 153 (1999).

[5] A. Gurevich, Enhancement of $\mathrm{rf}$ breakdown field of superconductors by multilayer coating, Appl. Phys. Lett. 88, 012511 (2006).

[6] C. James, M. Krishnan, B. Bures, T. Tajima, L. Civale, R. Edwards, J. Spradlin, and H. Inoue, Superconducting Nb thin films on $\mathrm{Cu}$ for applications in SRF accelerators, IEEE Trans. Appl. Supercond. 23, 3500205 (2013).

[7] T. L. Hylton, A. Kapitulnik, M. R. Beasley, J. P. Carini, L. Drabeck, and G. Gruner, Weakly coupled grain model of high-frequency losses in high Tc superconducting thin films, Appl. Phys. Lett. 53, 14, 1343 (1988).

[8] B. Bonin and H. Safa, Power dissipation at high fields in granular rf superconductivity, Supercond. Sci. Technol. 4, 257 (1991). 
[9] C. Attanasio, L. Maritato, and R. Vaglio, Residual surface resistance of polycrystalline superconductors, Phys. Rev. B 43, 7, 6128 (1991).

[10] V. Palmieri and R. Vaglio, Thermal contact resistance at the $\mathrm{Nb} / \mathrm{Cu}$ interface as a limiting factor for sputtered thin film rf superconducting cavities, Supercond. Sci. Technol. 29, 015004 (2016).

[11] S. Wilde, R. Valizadeh, O. B. Malyshev, N. P. Barradas, E. Alves, G. B. G. Stenning, A. Hannah, S. Pattalwar, and B. Chesca, High power impulse magnetron sputtering of thin films for superconducting rf cavities, in Proceedings of the 17th International Conference on rf Superconductivity, Whistler, Canada, 2015 (JACoW, CERN, Geneva, 2015).

[12] S. Wilde, R. Valizadeh, O. B. Malyshev, G. B. G. Stenning, A. Hannah, D. O. Malyshev, S. Pattalwar, and B. Chesca, Physical vapor deposition of thin films for use in superconducting rf cavities, in Proceedings of the 6th International Particle Accelerator Conference, Richmond, 2015 (JACoW, CERN, Geneva, 2015).

[13] S. Wilde, R. Valizadeh, O. B. Malyshev, A. Hannah, D. O. Malyshev, S. Pattalwar, G. B. G. Stenning, and B. Chesca, Development of thin films for superconducting rf cavities, in Proceedings of the 5th International Particle Accelerator Conference, Dresden, Germany, 2014 (JACoW, CERN, Geneva, 2014).

[14] A. Anders, J. Andersson, and A. Ehiasarian, High power impulse magnetron sputtering: Current-voltage-time characteristics indicate the onset of sustained self-sputtering, J. Appl. Phys. 102, 113303 (2007).
[15] A. Anders, Generalized structure zone diagram, Thin Solid Films 518, 4087 (2010).

[16] M. C. Burton, M. R. Beebe, K. Yang, R. A. Lukaszew, A. M. Valente-Feliciano, and C. Reece, Superconducting $\mathrm{NbTiN}$ thin films for superconducting radio frequency accelerator cavity applications, J. Vac. Sci. Technol. A 34, 021518 (2016).

[17] A. A. Zhukov, G. K. Perkins, V. Yu, V. Bugoslavsky, and A.D. Caplin, Geometrical locking of the irreversible magnetic moment to the normal of a thin-plate superconductor, Phys. Rev. B 2809 (1997).

[18] R. Kleiner and W. Buckel, Superconductivity (Wiley-VCH, Weinheim 2016).

[19] P. Esquinazi, A. Setzer, D. Fuchs, Y. Kopelevich, E. Zeldov, and C. Assmann, Vortex avalanches in $\mathrm{Nb}$ thin films: Global and local magnetization measurements, Phys. Rev. B 60, 12454 (1999).

[20] R. B. Goldfarb, L. F. Goodrich, T. Pyon, and E. Gregory, Suppression of flux jumps in marginally stable niobium-tin superconductors, IEEE Trans. Appl. Supercond. 11, 3679 (2001).

[21] D. K. Brice, J. Y. Tsao, and S. T. Picraux, Partitioning of ion-induced surface and bulk displacements, Nucl. Instrum. Methods Phys. Res., Sect. B 44, 68 (1989).

[22] H. Padamsee, The science and technology of superconducting cavities for accelerators, Supercond. Sci. Technol. 14, R28 (2001). 